\title{
Optimization of Process Parameters for Resistance Spot Welding Process of HR E-34 Using Response Surface Method - A Review
}

\author{
B. S. Gawai ${ }^{1}$, Dr. C. M. Sedani ${ }^{2}$ \\ ${ }^{1}$ PG Student, MSS'S, College of Engineering \& Technology, Jalna, M.S., India \\ ${ }^{2}$ Principal, MSS'S, College of Engineering \& Technology, Jalna, M.S., India
}

\begin{abstract}
Resistance spot welding process (RSW) is one of important manufacturing processes in automotive industry for assembling bodies. Quality and strength of the welds and therefore body mainly are defined by quality of the weld nuggets. Resistance Spot Welding (RSW) is widely used for its low cost, high speed, simple mechanism and applicability for automation. It depends on the resistance of the base metal and the amount of current flowing to produce the heat necessary to make the spot weld. There are various process parameters (weld current, weld time, electrode force) which affect the weld nugget and its strength. So it is necessary to optimize the process parameters of resistance spot welding process. Therefore it is very important to understand the behaviour of spot welds and their failure characteristics. This paper focus on response surface method to optimize the machining parameter of resistance spot welding that is (weld current, weld time, electrode force) which are responsible for Nugget diameter \& strength of the weld. The experimental studies have been conducted under varying welding current \& welding time, electrode force.
\end{abstract}

Keywords: Resistance Spot Welding (RSW), Response Surface Method (RSM), Tensile Shear Strength, Nugget Diameter, Hot rolled E34(HR E-34)

\section{Introduction}

Resistance spot welding (RSW) is a major sheet metal joining process in many industries, such as the automobile, domestic appliances, air craft and space craft fabrications. It is an efficient joining process widely used for the fabrication of sheet metal assemblies. There are 3000-6000 spot welds in any car, which shows the level importance of the resistance spot welding. RSW has excellent technoeconomic benefits such as low cost, high production rate and adaptability for automation which make it an attractive choice for auto-body assemblies, truck cabins, rail vehicles and home appliances. It is one of the oldest of the electric welding processes in use by industry today. Spot welding is one form of resistance welding, which is a method of welding two or more metal sheets together without using any filler material by applying pressure and heat to the area to be welded. The process is used for joining sheet materials and uses shaped copper alloy electrodes to apply pressure and convey the electrical current through the work pieces. In all forms of resistance welding, the parts are locally heated. The material between the electrodes yields and is squeezed together. It then melts, destroying the interface between the parts. The current is switched off and the "nugget" of a molten material solidifies forming the joint. The principle of resistance welding is based on Joule heating. The process is used extensively for joining low and mild carbon steel sheet metal components for automobiles, cabinets, furniture and similar products. Stainless steel, aluminum and copper alloys are also spot welded commercially.

\subsection{Introduction to Process}

There are various factors involves resistance spot welding process which are responsible for the quality of weld. Depending on the thickness and type of the metal, welding conditions such as weld current, weld time, electrode type and electrode force should be adjusted. Generally, a weld cycle can be divided into a number of stages in figure 1

- Pre-squeeze stage (1 to 2)

- Squeeze stage (2 to 3)

- Weld stage (3 to 4)

- Hold stage (4 to 5)

- Release stage (5 to 6 )

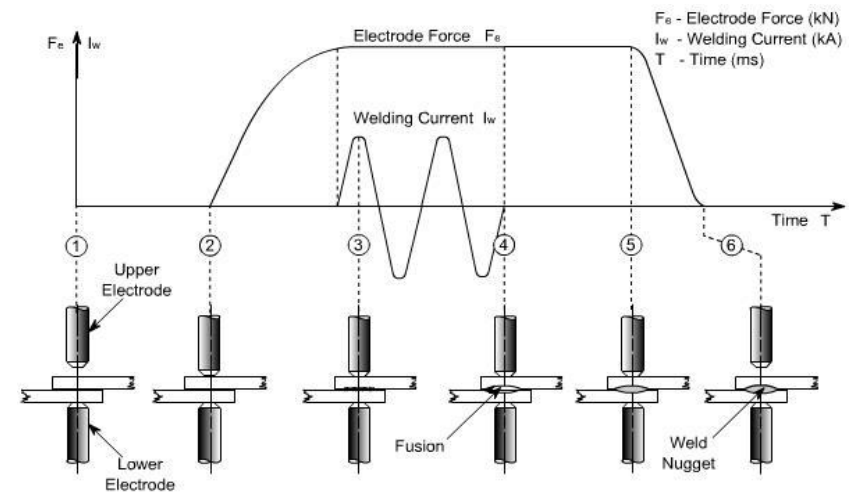

Figure 1: Welding Cycle of RSW process

In the Pre-squeeze stage, the moving electrode closes towards the work pieces, resulting in contact between the electrodes and work pieces. The velocity of the electrodes at this point of impact is very important considering that too high impact energy will results in excessive electrode wear. In the squeeze stage, the electrodes are forced on the work piece surfaces by means of the force actuating system and this offers the possibility to deform the work piece to ensure sound contact between them. In the weld stage, while force remains on the work pieces, current will be flowing through the electrodes and the work piece, heating up every part in the secondary weld circuit proportional to the effective 


\section{International Journal of Science and Research (IJSR) \\ ISSN (Online): 2319-7064}

Index Copernicus Value (2013): 6.14 | Impact Factor (2014): 5.611

resistance present at each point. In the hold stage, the current is cut off and produced weld is allowed to solidify and cool down under maintain pressurizing force. After sufficient holding time, the electrodes release the work piece and the cycle is complete. The major advantages of the resistance welding processes over any other welding process is the feature that heat necessary for weld formation is generated at the exact location where the joints needs to appear. The possibility to highly reduce the time to complete a weld resulting in cycle times being competitive over other welding process. The another advantage is the absence of a molten weld pool penetrating from one side through a work piece, resulting in less aesthetical damage to the work piece surfaces.

\subsection{Important parameters of Resistance Spot Welding (RSW)}

The three main parameters in spot welding are current, contact resistance and weld time. In order to produce good quality weld the above parameters must be controlled properly. The magnitude of the current, the resistance of the current conducting path, and the time for which the current is made to flow account for the heat generated in the work piece. This can be expressed in terms of Joule heating, by the simple application of Ohm's law the voltage (V) required for a current flow (I) is given by the relationship

$\mathrm{V}=\mathrm{IR}$

Where, $\mathrm{R}=$ Resistance offered by the work piece to the flow of current.

Therefore the Heat generated is expressed by the formula,

$\mathrm{H}=\mathrm{IVt}$

$\mathrm{H}=\mathrm{I}(\mathrm{IR}) \mathrm{t}$

$\mathrm{H}=\mathrm{I}^{2} \mathrm{Rt}$

Where, $\mathrm{H}=$ Heat generated in Joules

$\mathrm{I}=$ Current in Amperes

$\mathrm{R}=$ Resistance in Ohms

$\mathrm{t}=$ Time of current flow in seconds

The heat generated is therefore directly proportional to the resistance offered by any point in the circuit. The interface of the two sheets forming a lap joint is the point of greatest resistance, and is therefore the point of greatest heat generation. Low voltage high amperage current is made to flow from one sheet to another sheet until the metal at the interface is heated to a temperature high enough to cause localized fusion which under the applied pressure squeezes the molten metal from the two parts to a homogeneous mass called the weld nugget. The amount of current needed for welding is inversely proportional to the duration of time and directly proportional to the area in contact. There are various parameters which directly or indirectly controls the quality of resistance spot welding. These are diagrammatically as shown in Fig. 2

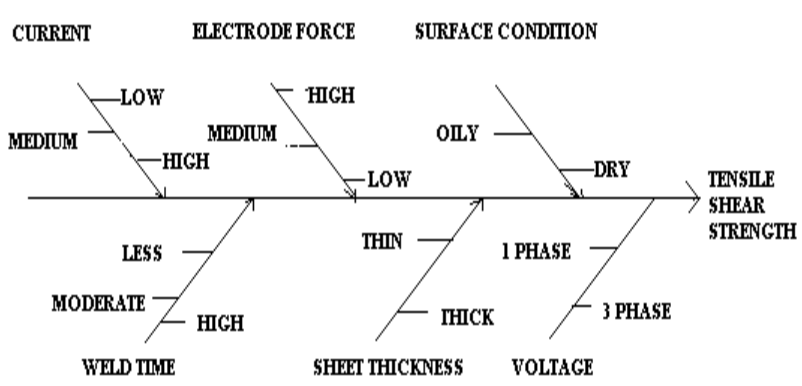

Figure 2: Ishikawa Cause and effect diagram

\section{a) Effect of welding current}

The current has more influence on the amount of heat generated. Tensile shear strength increases rapidly with increasing current density. Excessive current density will cause molten metal expulsion (resulting in internal voids), weld cracking, and lower mechanical strength properties. In case of spot welding, Excessive current will overheat the base metal and result in deep indentations in the parts.

\section{b) Effect of weld time}

The total heat developed is proportional to weld time. During a spot welding operation, some minimum time is required to reach melting temperature at some suitable current density. Excessively long weld time will have the same effect as excessive amperage on the base metal and electrodes.

\section{c) Effect of welding pressure}

As the pressure is increased, the contact resistance and the heat generated at the interface will decrease. To increase the heat to the previous level, amperage or weld time must be increased to compensate for the reduced resistance. Contact resistance will be high. As the pressure is increased, the high spots are depressed and the actual metal-to-metal contact area is increased, thus decreasing the contact resistance.

\section{d) Effect of welding voltage}

Welding voltage don't have the significant affect on the heat developed, cleared by the heat develop formula. It is used to choose the welding operation on single or double phase mode.

\section{e) Effect of Weld force}

Weld force is another important parameter of resistance spot welding. Welding force affects the contact resistance and contact area at the weld interface. The proper and consistent welding force improves the mating of the materials, increasing the current paths, reducing the interface resistance and also removes oxides barriers between work pieces.

\section{f) Effect of Material properties}

Normally all material properties are changes with respect to temperature. Resistivity of material, thermal conductivity and heat capacity of the material affects the heat generation during welding process. Hardness of the material also affects the contact resistance at weld surface. Harder materials having high contact resistance for the same weld force.

\section{g) Effect of Surface coatings}

Materials surfaces are offered by some kind of corrosion resistant surface coatings. These surface coatings also affect 


\section{International Journal of Science and Research (IJSR) \\ ISSN (Online): 2319-7064 \\ Index Copernicus Value (2013): 6.14 | Impact Factor (2014): 5.611}

the welding process. Separate adjustments of process parameters are made according to the individual type of surface coatings. Surface coatings are selected systematically to make the favourable welding conditions at weld surface.

\subsection{Problem Statement}

Generally, the quality of a weld joint is directly influenced by the welding input parameters during the welding process; therefore, welding can be considered as a multi-input multioutput process. Unfortunately, a common problem that has faced the manufacturer is the control of the process input parameters to obtain a good welded joint with the required bead geometry and weld quality with minimal detrimental residual stresses and distortion. Traditionally, it has been necessary to determine the weld input parameters for every new welded product to obtain a welded joint with the required specifications. To do so, requires a time-consuming trial and error development effort, with weld input parameters chosen by the skill of the engineer or machine operator. Then welds are examined to determine whether they meet the specification or not. Finally the weld parameters can be chosen to produce a welded joint that closely meets the joint requirements. The qualities of the spot welded joints are defined by the mechanical properties and size of the heat affected zone.

\section{Common Weld Problems in Resistance Spot Welding}

- Spot burn and deep indentation are two basic defects which occur more probably during welding run.

- Excessive heat in the electrodes reduces the electrode cap life and deteriorates the weld quality.

- In the case of spot welding excessive current will overheat the base metal and result in deep indentations in the parts and, it will cause overheating

- and rapid deterioration of the electrodes.

- Tensile shear strength increases rapidly with increasing current density. Excessive current density will cause molten metal expulsion, weld cracking, and lower mechanical strength properties.

- Resistance Spot Welding, the weld quality is best judged by Nugget Size and Joint Strength. It is important to select the welding process parameters for obtaining optimal size of Weld Nugget.

- This does not ensure that the selected welding process parameters can produce the optimal weld nugget for that particular welding Machine and Environment.

- As the main objective of the Manufacturing process is always to improve the overall quality of a product, it is necessary to optimize multiple quality characteristics simultaneously.

- The increase in welding time and decrease in electrode force have been found to increase the weld nugget growth and the tensile shear strength until the occurrence of expulsion. Therefore suitable combination of these parameters, called the welding schedule, is required to achieve a spot weld with the desired weld characteristics (nugget diameter, tensile shear strength and indentation).

Quality of weld depending upon the weld current, weld time, electrode type and electrode force should be adjusted. Actual in practice "20 to 30 "percent of these spot welds contains uncertainty in quality of spot welds, hence external pushup required to optimize these welding process.

\subsection{Flow Chart of Work and Methodology}

Methodology employed for the successful conduction of experiments is explained by the flow diagram as below

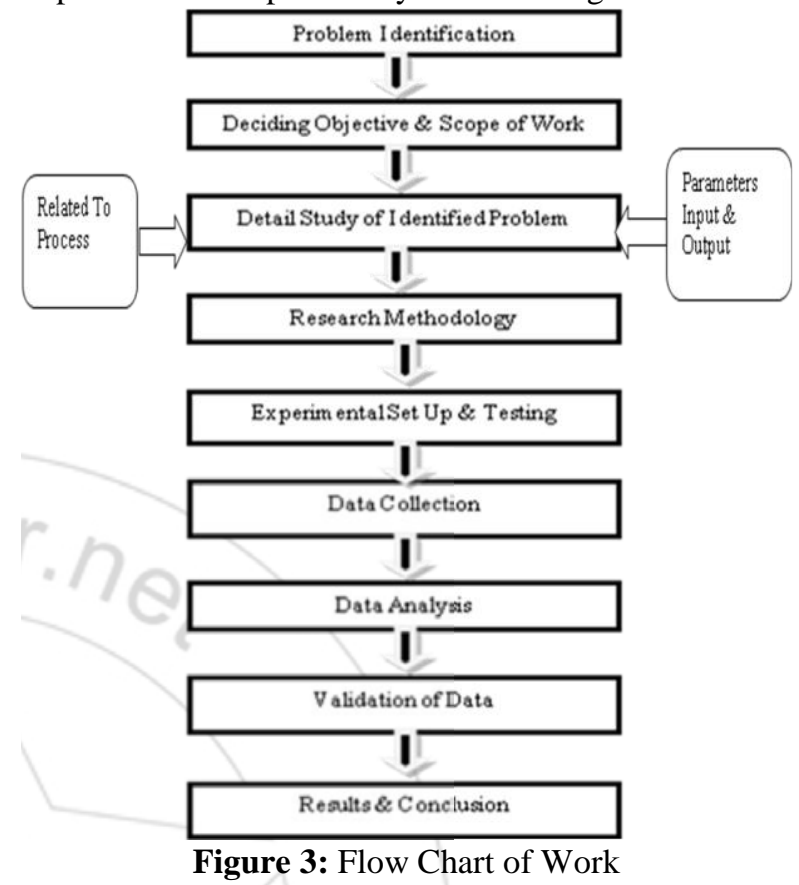

\section{Response Surface Methodology (RSM)}

Response surface methodology is a collection of statistical and mathematical methods that are useful for the modeling and analyzing engineering problems. In this technique, the main objective is to optimize the response surface that is influenced by various process parameters. Response surface methodology also quantifies the relationship between the controllable input parameters and the obtained response surfaces. The RSM (Response Surface Method) is important in designing, formulating, developing \& analyzing new scientific studying and products. It is also efficient in the improvement of existing studies and products. The common applications of RSM are in Industrial, Biological \& Clinical Science, Social Science, Food Science, and Physical \& Engineering Science.

\section{Literature Review}

The review presented in this section is on different techniques proposed and investigated by researchers resulting in the improvement in Nugget diameter and Weld Strength. Scrutiny of the published research work emphasized the need for such a review reporting all the available literature and suggesting the future direction for research. The present survey explores different methodologies and processes regarding the enhancement of responses like Nugget diameter and Tensile Strength. The Survey is given as: A.G.Thakur, V.M.Nandedkar [1], "Application of Taguchi method for Resistance Spot Welding of Galvanized Steel", carried out an experimental 0vestigation for optimization of Tensile Shear (T-S) strength of RSW for Galvanized steel using Taguchi method. The 


\section{International Journal of Science and Research (IJSR) \\ ISSN (Online): 2319-7064 \\ Index Copernicus Value (2013): 6.14 | Impact Factor (2014): 5.611}

experimental studies were conducted under varying welding current, welding time, electrode diameter and electrode force. Based on the ANOVA method, the highly effective parameters on tensile shear strength were found as welding current and welding time, whereas electrode force and electrode diameter were less effective factors. The results showed that welding current was about two times more important than the second factor weld time for controlling the tensile shear strength.

Uğur Esme [2], “Application of Taguchi Method for the Optimization of Resistance Spot Welding Process", aimed to optimize RSW process parameters for SAE 1010 Steel using Taguchi method. He used SAE 1010 steel sheets material with different thicknesses. For the use of Taguchi method to determine the process parameters in the spot welding of SAE 1010 steel sheets. According to the analysis, the most effective parameters with respect to tensile shear strength is welding current, electrode force, electrode diameter, and welding time. Based on the ANOVA method, the highly effective parameters on tensile shear strength were found as welding current and electrode force, whereas electrode diameter and welding time were less effective factors.

D.S.Sahota et.al [3], "Study of Effect of Parameters on Resistance Spot Weld of ASS316 Material", aimed to study the effect of parameters on resistance spot weld of ASS316 material. It is clear from the results that parameters significantly affect both the mean and the variation in the percentage improvement in Hardness values of the ASS316 material. An increase in weld current, weld time and electrode force results in an increase in weld nugget diameter and width. An increase in weld current, weld time and electrode force results in an increase in electrode indentation.

J.B. Shamsul and M.M. Hisyam [4], "Study of Spot Welding of Austenitic Stainless Steel Type 304", concluded experimental study of austenitic stainless steel type 304 was welded by resistance spot welding. They used Austenitic SS304 of 3mm thickness. The experimental results to shows, that the changes of the current, the nugget diameter were changed. So it is proven that the weld nugget increases with the increasing of welding current. The results show that increasing welding current increased the nugget size. The nugget size does not influence the hardness distribution. In addition, increasing welding current does not increase the hardness distribution.

Darwish et al. [5], "Statistical models for spot welding of commercial stainless steel sheets", on this study paper, He has developed a mathematical model to study the influence of spot welding parameters (welding current, welding time, electrode force and sheet thickness) on the strength of spot welded Stainless steel sheets with commercial purity. Experiments were planned on the basis of Response Surface Methodology (RSM) technique. The mathematical models (failure load and nugget area) co-relating process parameters and their interactions with the response parameters have been established. These models have been used in selecting the optimum process parameters for obtaining the desired spot welding quality at the least possible consumed power.
M. Hamedi et al. [6], "Numerical study of nugget formation in Resistance spot welding", aimed to numerical study of nugget formation in resistance spot welding. They concluded that as the welding process continues temperature of sheets interface rises quickly until this area melts and nugget forms. After the formation of nugget, rate of temperature rise is reduces. At the end of welding time, as current switches off, the weldment starts to cool dawn. And at low electrode forces and high welding currents, the formed fusion zone is large.

Gyanendra Singh et al. [7], "Effect of weld current and time on hardness of spot weld", aimed to study the impacts of weld current and weld time on the heat affected zone (HAZ) hardness of spot weld. They used Austenitic stainless steel grade 304, 304L, 304H. The austenitic structure also gives these grades excellent toughness, even down to cryogenic temperatures. For the experimental work, to improve the reliability of results that using on the basis of response surface methodology (RSM) technique. At last the results shown that Hardness of heat affected zone (HAZ) decreases with increase in weld current and weld time. The effect of weld current and weld time on weld nugget diameter, width of HAZ and degree of electrode indentation can also be examined.

A. Ambroziak et al. [8], "Using resistance spot welding for joining aluminium elements in automotive industry", presented resistance spot welding of Aluminium alloys. Automotive Industry tends to use light alloys like Aluminium and magnesium alloys. Companies more often use Aluminium as an alternative material for vehicle body. The most popular method of joining body sheets is resistance spot welding. Aluminium and its alloys series $5 x x x$ and $6 x x x$ can be connected by this technique. It requires high power welding gun and precocious steering of current and time. The aspects of rapid deterioration of tips must be taken into account.

Majid Pouranvari [9], "Prediction of failure mode in AISI 304 resistance spot welds", experimentally studied failure mode of AISI304 resistance spot welds is studied under quasi static tensile-shear test. He concluded that failure location for AISI 304 RSW in pullout failure mode is at $\mathrm{HAZ}$, adjacent to the weld nugget Low fusion zone hardness to failure location hardness ratio increases the tendency of spot weld failure to occur in the interfacial failure mode during the tensile-shear test. Metallurgical characteristics of welds should be considered to predict and analyze the spot weld failure mode more precisely.

Norasiah Muhammad et al. [10], “Model Development for Quality Features of Resistance Spot Welding Using Multiobjective Taguchi Method and Response Surface Methodology", presented the use RSM for employed to develop the mathematical model for predicting the weld zone development. To validate the predicted model, experimental confirmation test was conducted for plate thickness of 1 and $1.5 \mathrm{~mm}$ (Low Carbon Steel). According to the analysis, it shows that weld current was statistically significant and the percentage contribution of different control factors on multiple quality characteristics (radius of weld nugget and width of HAZ). In RSW, welding current 


\section{International Journal of Science and Research (IJSR) \\ ISSN (Online): 2319-7064 \\ Index Copernicus Value (2013): 6.14 | Impact Factor (2014): 5.611}

and contact surface have the greatest effect on the growth of weld nugget. Based on the results, the developed model can be effectively used to predict the size of weld zone which can improve the welding quality and performance in RSW.

Panchakshari et al. [11], "Comparative Study of Responses of Resistance Spot Welding Obtained from Genetic Algorithm, Response Surface and D- Optimal Method", performed comparative study of responses of resistance spot welding process obtained from three methodologies of Genetic algorithm, Design of Experiments and Response surface method. Low carbon steel is used as a testing material for this research work. Mathematical model developed by using regression analysis and ANOVA. Weld cycle and welding current are most effective factors for welding to obtain above mentioned values of nugget diameter and strength of weld, both these variables should be at middle values of their range at 12 cycles and $11.2 \mathrm{KA}$ respectively. Hold cycle time is less significant, to obtain optimal result it should always at it mid value of range that is 20 cycle. Squeeze cycle take part in formation of nugget diameter and to maintain strength of weld it should be at its high value of range equal to 30 cycles.

Aravinthan and Sivayoganathan [12], "A Neural Network system For Spot Weld Strength Prediction", explored change in welding schedule gives changes in current with time at constant pressure shows changes in the amplitude in both the current and voltage wave forms .Experiments results that welding strength increases as increasing in welding current for same amount of welding pressure. Neural Network system used for prediction of strength of weld. NSS mapped the welding parameter to its respective weld strength based on lot of test pattern during learning process. The dynamic resistance was found to reduce the welding current is increased. The resistance will increase till certain value of nugget diameter and finally resistance decreases duet to overheat produced by current which melts the contaminants.

S.P.Tewari et al. [13], "Resistance spot weldability of low carbon and HSLA steels ", carried out welding done separately on three different stages firstly on low carbon steel, secondly on high strength low alloy steel and after that combination of these two. During experiments welding current has been changed but other parameter kept constant. Focused on to find out relation of bearing capacity, hardness and weld nugget with welding current. Outcomes from this research the weld ability of low carbon steel is more than HSLA steel followed by combination of these materials. The hardness of HSLA steel is more than low carbon steel hence electrode force doesn't get transferred properly on the weld zone and causes deeper electrode penetration in metal. The rate of increase in current with nugget diameter is proportionate in low carbon steel but sudden in HSLA steel.

Bhosle and Kadam [14], "Prediction of Surface Roughness and Material Removal Rate of surface Grinded Jobs through RSM based Models", Considered Surface roughness and material removal rate as the output parameters against feed and depth of cut as input parameters. Response surface methodology has been considered for developing the mathematical models central composite design defined the five levels of input process parameters for high chromium high carbon die steel materials. Result come out from work that depth of cut increases, material removal rate decreases by keeping feed at constant level and as the depth of cut increases, the surface roughness also increases with keeping values of feed at constant level.

Elangovan et al. [15], "Experimental investigations on optimization of ultrasonic welding parameters for copper to brass joints using response surface method and genetic algorithm", aimed optimize specimen of two dissimilar materials mainly copper and brass. The joining process of specimen is ultrasonic spot and seam welding process. Outcome from this experiments shows that, in case of spot welding strength increases with weld time for any value of pressure because weld time gives sufficient time for good metal contact by van der Waals forces. Weld strength also increases with increase in weld time and amplitude because amplitude gives maximum area. In case of seam welding, strength increases with weld time up to certain limit. Beyond that strength decreases because it changes the orientation of bonding \&they get stretched. The result obtained from response methodology is closely matched with experimental result.

Ulas Caydas et al. [16] presented the use of adaptive neurofuzzy inference system method based on the full factorial experimentation for prediction of surface roughness and white layer thickness in the wire electro discharge machining. Normalization, feature reduction and ANFIS tests were performed to predict the desired responses. As a result, this approach greatly improved the process responses such as surface roughness and white layer thickness in the wire electrical discharge machining process.

K. Pandey, M. I. Khan, K. M. Moeed. [17] “Optimization of Resistance Spot Welding Parameters Using Taguchi Method". In this research they have been represents the optimization of various process parameters of resistance spot welding process. The material used is low carbon cold rolled 0.9mm mild steel sheets (AISI 1008/ASTM A366). For the experimental setup and investigation of varying process parameters (welding current, welding pressure, and welding time) to effect of the quality characteristic (tensile strength) using Taguchi Method. An experimental result shows that, $\mathrm{S} / \mathrm{N}$ ratio to tensile strength indicates the welding current to be the most significant parameter that controls the weld tensile strength where the holding time and pressure are less. The contribution of Welding current, holding time and Pressure towards tensile strength is $61 \%$, $28.7 \%$, and $4 \%$ determined by the ANNOVA method.

Norasiah Muhammad and Yupiter HP Manurung[18], "Design parameters selection and Optimization of weld zone development in Resistance Spot Welding". The work piece material used in this study was $1.21 \mathrm{~mm}$ thick coated low carbon steel as the base metal. A general $2^{4}$ factorial design augmented by 5 centre points was used to study the effect of factors namely weld current, weld time, electrode force and hold time on the development of weld zone. Optimization of the significant parameters affecting the development of weld zone obtained from the factorial design was carried out using CCD (Central Composite Design) in Response Surface 


\section{International Journal of Science and Research (IJSR) \\ ISSN (Online): 2319-7064 \\ Index Copernicus Value (2013): 6.14 | Impact Factor (2014): 5.611}

Method. On the results define that all the selected factors expect hold time affected the radius of weld nugget and HAZ (Heat Affected Zone) significantly and optimized using the Central Composite Design by RSM. The experimental results obtained under optimum operating conditions were compared with the predicted values and found to agree satisfactorily with each other.

Chinmoy Mondal et al.[19],'Parametric optimization of Spot welding of 17-4 Ph Stainless Steels using the Analytic Hierarchy Process", attempted optimization of spot welding of $0.6 \mathrm{~mm}$ thick $17-4$ precipitation hardening stainless steel by using the analytic hierarchy process and obtained good weld nuggets with a current of $2.5 \mathrm{KA}$, for a welding time of 6 to 7 cycles and also with another current value of 6 to 7 $\mathrm{KA}$ with a welding time of 5 cycles keeping load as constant at $4 \mathrm{KN}$.

Nachimani Charde et al.[20],'Investigating spot weld growth on 304 austenitic stainless steel $(2 \mathrm{~mm})$ sheets", in a paper ,on investigation of spot weld growth on 304 austenitic stainless steel $(2 \mathrm{~mm})$ sheets, reported that the growth of a spot weld is primarily determined by its parameters such as current, weld time, electrode tip and force. This paper is intended to analyze only the effects of nuggets growth due to the current and weld time increment with constant force and unchanged electrode tips. He reported that the hardness of welded zones is greater than the hardness of the un-welded zone and also the heat affected zones.

\section{Conclusion and Discussion}

From the literature it is found there are remarkable works carried out in the field of process parameter optimization for the material like stainless steel and aluminium. But that work carryout only for limited materials not for other material. The literature above reveals that the lot of efforts was taken in order to rationalize the RSW process. RSW process experimental work has been carried out by researchers for process parameters like welding current, welding time and squeezes time and hold time, Electrode Pressing force, electrode geometry, the choice of electrode material. Also research has been done for product parameters like penetration, heat affected zone, sheet thickness, Overlapping length, strength of weld and distortion stresses. The findings of literature review is Little work has been reported on the modeling and analysis of effects of Welding parameters on the performance characteristic in RSW process of Cold rolled steel grade CR1, CR-2, CR-3. The literature survey infers that there is a need to study the effects of all process parameters on the weld quality and weld strength in detail. At the some of the research papers concluded that current is the major factor to affect of the weld quality and weld strength by increasing/decreasing others parameters.

\section{References}

[1] A.G.Thakur, T.E.Rao, M.S.Mukhedkar, V.M.Nandedkar, "Application of Taguchi method for Resistance Spot Welding of Galvanized Steel", APRN
Journal of Engineering and Applied Sciences, vol.5 november-2010. pp. 22-25.

[2] Ugur Esme, "Application Of Taguchi Method For The Optimization Of Resistance Spot Welding Process" Mersin University, Tarsus Technical Education, Faculty Department of Machine Education 33400 Tarsus/Mersin, Turkey. The Arabian Journal for Science and Engineering, Volume 34, Number 2B. October 2009.pp.521-524

[3] D.S.Sahota, Ramandeep Singh, Rajesh Sharma, "Study of Effect of Parameters on Resistance Spot Weld of ASS316 Material “, Mechanica Cofab 2013, Vol.2, No. 2, pp. 68-77.

[4] J.B. Shamsul and M.M. Hisyam, "Study of Spot Welding of Austenitic Stainless Steel Type 304" School of Materials Engineering, University Malaysia Perlis, Journal of Applied Sciences Research, 2007, INSI net Publication. pp.1494-1499.

[5] Darwish S.M and Al-Dekhial S.D (1998), "Statistical models for spot welding of Commercial stainless steel sheets", International Journal of machine tool and manufacture,39, pp. 1589-1610.

[6] Gyanendra Singh, Dheeraj Sagar, Rajeev Arora, Nishant Singh, "Effect of Weld Current and Time on HAZ hardness of Spot Weld" Department of Mechanical Engineering , Inverts University Bareilly.

[7] M.Hamedi and H.Pashazadeh (2008), "Numerical study of nugget formation in resistance spot welding", International Journal of Mechanics, issue 1, Volume 2.

[8] A. Ambroziak, M. Korzeniowski (2010), "Using resistance spot welding for joining aluminium elements in automotive industry", archives of civil and mechanical engineering, Vol. X, pp. 5-13.

[9] Majid Pouranvari (2011), "Prediction of failure mode in AISI 304 resistance spot welds", Association of Metallurgical Engineers of Serbia, UDC: 621.791.763, pp. 23-29.

[10] Norasiah Muhammad · Yupiter H. P. Manurung •Roseleena Jaafar,"Model Development for Quality Features Of Resistance Spot Welding Using Multiobjective Taguchi Method And Response Surface Methodology" Faculty of Mechanical Engineering, MARA University of Technology (UiTM), 40450Springer Science+Business Media, LLC 2012. pp. 2365-2370.

[11] A.S.Panchakshari ,Dr.M.S.Kadam “Comparative Study of Responses of Resistance Spot Welding Obtained From Genetic Algorithm, Response Surface and DOptimal Method'International Journal of Engineering Science and Innovative Technology (IJESIT) Volume 2, Issue4, July 2013, ISSN: 2319-5967).

[12] Aravinthan and Sivayoganathan, "A Neural Network system For Spot Weld Strength Prediction", Journal of Material and Technology, Vol-15, January-March 2010.pp.1-10.

[13] S.P.Tewari. Nitin Rathod, "Resistance spot weldability of low carbon and HSLA steels", published in Thammasat International Journal of Science\& Technology, Vol-15, 2010. pp1-11.

[14] S.Bhosle, M.S.Kadam, "Prediction of Surface Roughness and Material Removal Rate of Surface Grinded Jobs Through RSM based Models" Published in International Conference of Advances in 


\section{International Journal of Science and Research (IJSR) \\ ISSN (Online): 2319-7064}

Index Copernicus Value (2013): 6.14 | Impact Factor (2014): 5.611

Manufacturing and Technology Management, January2007.pp.507-511.

[15] S.Elangovan,S.Venkateshwaran, "Experimental Investigation on Optimization of Ultrasonic Welding Parameters for Copper to Brass joint using Response surface Method and Genetic Algorithm" Published in International Journal of Advanced Engineering Research and Studies,Vol-1,pp55-64,April-June-2012.

[16] Ulas Caydas, Ahmet Hascalik, Sami Ekici,“An adaptive neuro-fuzzy inference system (ANFIS) model for wire EDM", Expert system with Applications (2009),Volume36, pp.6135-6139.

[17] A. K. Pandey, M. I. Khan, K. M. Moeed "Optimization Of Resistance Spot Welding Parameters Using Taguchi Method" Integral University, Lucknow, India. International Journal of Engineering Science and Technology (IJEST), ISSN: 0975-5462 Vol. 5 No.02 February 2013.

[18] Norasiah Muhammad \& Yupiter HP Manurung "Design Parameters Selection And Optimization Of Weld Zone Development In Resistance Spot Welding" World Academy of Science, Engineering and Technology 71 2012.

[19]Chinmoy Mondal,Subhajit Bhattacharya ,Santanu Das,"Parametric optimization of Spot welding of 17-4 $\mathrm{Ph}$ Stainless Steels using the Analytic Hierarchy Process", Indian Welding Journal,Oct2011,69-77.

[20] Nachimani Charde and Rajprasaad Rajkumar,"investigating spot weld growth on 304 austenitic stainless steel $(2 \mathrm{~mm})$ sheets, Journal of Engineering Science and Technology Vol. 8, No. 1 (2013) 69 - 76 , (C) School of Engineering, Taylor's University. 